\title{
Head size and intelligence, learning, nutritional status and brain development Head, IQ, learning, nutrition and brain
}

\author{
Daniza M. Ivanovic ${ }^{\mathrm{a}, *}$, Boris P. Leiva ${ }^{\mathrm{a}}$, Hernán T. Pérez ${ }^{\mathrm{a}}$, Manuel G. Olivares ${ }^{\mathrm{a}}$, Nora S. Díaz ${ }^{\mathrm{a}}$, \\ María Soledad C. Urrutia ${ }^{b}$, Atilio F. Almagià ${ }^{c}$, Triana D. Toro ${ }^{c}$, Patricio T. Miller ${ }^{d}$, \\ Enrique O. Bosch ${ }^{\mathrm{d}}$, Cristián G. Larraín ${ }^{\mathrm{d}}$ \\ a Public Nutrition Area, Institute of Nutrition and Food Technology (INTA), University of Chile, Avda. Macul 5540, P.O. Box 138-11, Santiago, Chile \\ ${ }^{\mathrm{b}}$ Pan American Health Organization (PAHO), Pan American Sanitary Bureau, Regional Office of the World Health Organization, Washington, DC, USA \\ ${ }^{c}$ Laboratory of Physical Anthropology and Human Anatomy, Institute of Biology, Catholic University of Valparaíso, Avda. Brasil 2959, Valparaíso, Chile \\ ${ }^{\mathrm{d}}$ Department of Magnetic Resonance Imaging Service, German Clinic of Santiago, Avda. Vitacura 5951, Santiago, Chile
}

Received 22 September 2003; accepted 17 November 2003

\begin{abstract}
This multifactorial study investigates the interrelationships between head circumference (HC) and intellectual quotient (IQ), learning, nutritional status and brain development in Chilean school-age children graduating from high school, of both sexes and with high and low IQ and socio-economic strata (SES). The sample consisted of 96 right-handed healthy students (mean age $18.0 \pm 0.9$ years) born at term. $\mathrm{HC}$ was measured both in the children and their parents and was expressed as Z-score (Z-HC). In children, IQ was determined by means of the Wechsler Intelligence Scale for Adults-Revised (WAIS-R), scholastic achievement (SA) through the standard Spanish language and mathematics tests and the academic aptitude test (AAT) score, nutritional status was assessed through anthropometric indicators, brain development was determined by magnetic resonance imaging (MRI) and SES applying the Graffar modified method. Results showed that microcephalic children $(Z-H C \leq 2$ S.D.) had significantly lower values mainly for brain volume (BV), parental $Z$-HC, IQ, SA, AAT, birth length (BL) and a significantly higher incidence of undernutrition in the first year of life compared with their macrocephalic peers $(Z$-HC $>$ 2 S.D.). Multiple regression analysis revealed that BV, parental Z-HC and BL were the independent variables with the greatest explanatory power for child's $Z$-HC variance $\left(r^{2}=0.727\right)$. These findings confirm the hypothesis formulated in this study: (1) independently of age, sex and SES, brain parameters, parental HC and prenatal nutritional indicators are the most important independent variables that determine $\mathrm{HC}$ and (2) microcephalic children present multiple disorders not only related to BV but also to IQ, SA and nutritional background.
\end{abstract}

(C) 2004 Elsevier Ltd. All rights reserved.

Keywords: Head; Brain; Intelligence; Nutrition assessment; Magnetic resonance imaging; Education

\section{Introduction}

Our previous studies reveal that head circumference, the anthropometric index of both nutritional background and brain development, is the most relevant physical index associated with scholastic achievement and intellectual ability in Chilean school-age children (Ivanovic, Forno, Castro, \& Ivanovic, 2000b; Ivanovic, Ivanovic, Truffello, \& Buitrón, 1989; Ivanovic, Olivares, Castro, \& Ivanovic, 1996; Toro, Almagià, \& Ivanovic, 1998). A "normal" head

\footnotetext{
* Corresponding author. Tel.: +56-2-678-1459; fax: +56-2-221-4030.

E-mail addresses: inta8@abello.dic.uchile.cl,daniza@uec.inta.uchile.cl (D.M. Ivanovic).

URL: http://www.inta.cl.
}

circumference, mean \pm 2 standard deviations, could be more related to statistical normality, although this may not be the case for psychological function or educational achievement (Ivanovic et al., 2000b). Despite the fact that microcephaly and macrocephaly are considered reliable indicators of brain pathology, head circumference values below the mean are associated with an increased incidence of lower intellectual abilities. This means that small differences in head size could be important in the interrelationship head circumference-intelligence-learning (Ivanovic et al., 2000b; Menkes, 1995).

The explanatory power of head circumference on intellectual ability and scholastic achievement variances increases significantly from the onset of elementary school until the end of high school, in contrast, the explanatory 
power of body weight and body height decrease significantly (Ivanovic et al., 1996, 2000b). Even more, school dropout correlates with head circumference and not with weight or height; at the onset of elementary school $59 \%$ of children had suboptimal head circumferences, percentage that decreased significantly to $40 \%$ in high school graduates (Ivanovic et al., 1996).

The relationships between head circumference, brain development and intelligence have been studied since the time of Broca and Galton, who concluded that variations in brain size (estimated indirectly by measuring head circumference) are related with intelligence (Vernon, Wickett, Bazana, \& Stelmack, 2000). Throughout the XX century, many investigators tried to establish the biological basis of human intelligence. The findings of several of these studies demonstrated a positive and significant correlation between head circumference, brain size and intelligence (Botting, Powls, Cooke, \& Marlow, 1998; Desch, Anderson, \& Snow, 1990; Dolk, 1991; Ivanovic et al., 2000a,b,d; Nelson \& Deutschberger, 1970; Ounsted, Moar, \& Scott, 1988; Reiss, Abrams, Singer, Ross, \& Denckla, 1996; Rushton, 2000; Strauss \& Dietz, 1998; Vernon et al., 2000; Willerman, Schultz, Rutledge, \& Bigler, 1991). Even in the elderly, head circumference has been found to positively and significantly correlated with intelligence. In this context, some authors have emphasised that bigger heads or brains may protect people against intellectual impairment (Schofield, Logroscino, Andrews, Albert, \& Stern, 1997; Tisserand, Bosma, Van Boxtel, \& Jolles, 2001).

Some authors have reported a non-significant association between brain size and intelligence. Many of these studies provided controversial evidence about the relationship between brain size and intelligence and some of them, carried out in monozygotic twins or sisters, did not find any association between these variables (Schoenemann, Budinger, Sarich, \& Wang, 2000; Teasdale \& Pakkenberg, 1988; Yeo, Turkheimer, Raz, \& Bigler, 1987). Nevertheless, recent findings from other investigators, also in monozygotic and dizygotic twins, found a positive correlation between brain size and intelligence (Anderson, 1999; Pennington et al., 2000). Therefore, genetic and environmental factors could affect brain development, intelligence and head circumference, besides this, could determine prenatal and postnatal nutritional status and educational attainment (Baker, Treloar, Reynolds, Heath, \& Martin, 1996; Casto, DeFries, \& Fulker, 1995; Luke, Keith, \& Keith, 1997; McGue \& Bouchard, 1998; Strauss \& Dietz, 1998; Weaver \& Christian, 1980).

Several communications have described that head circumference in the first year of life may predict later intelligence (Botting et al., 1998; Nelson \& Deutschberger, 1970). In this respect, the interrelationship between intelligence and nutritional background, reflected by a decreased head circumference, can be affected by birth weight and other variables (Botting et al., 1998; Ivanovic, 1996; Ivanovic et al., 1989, 1996, 2000a,d, 2002; Leiva et al., 2001; Matte, Bresnahan, Begg, \& Susser, 2001; Pennington et al., 2000;
Reiss et al., 1996; Rushton, 2000; Sorensen et al., 1999; Stathis, O'Callaghan, Harvey, \& Rogers, 1999; Stoch, Smythe, Moodie, \& Bradshaw, 1982; Toro et al., 1998; Vernon et al., 2000; Willerman et al., 1991). However, other authors found that impaired fetal growth was not associated with poorer cognitive performance in adult life; adaptations made by the fetus in response to conditions that retard growth seem to be largely successful in maintaining brain development (Martyn, Gale, Sayer, \& Fall, 1996).

Intelligence has been described as the best predictor of school achievement (Ivanovic et al., 1989, 2000a,c,d, 2002) and significantly explained by maternal intellectual quotient (IQ), by brain volume and nutritional status during the first year of life, as we reported previously in the sample evaluated for the present study (Ivanovic et al., 2002); this has been observed independently of age, sex and socio-economic stratum (SES). Results from other studies carried out by us in Chilean school-age children to determine the interrelationship between intellectual ability and socio-economic, cultural, family, mass media exposure, demographic and educational factors showed maternal schooling was the variable with the greatest explanatory power in intellectual ability variance (Ivanovic, Forno, \& Ivanovic, 2001).

The impact of early childhood malnutrition on head circumference, brain development and later on intelligence is still a matter of controversy due to the fact that these variables are influenced by socio-economic and cultural factors that are co-determinants of intelligence, of nutritional status and of brain development; head circumference below -2 S.D. of the mean may be an indicator of severe undernutrition and accurately reflects retarded brain growth during the first year of life (Winick \& Rosso, 1969a). The long-term effects of severe undernutrition at an early age may result in delayed head circumference growth, delay of brain development and decreased intelligence and scholastic achievement, variables that are strongly interrelated (Grantham-McGregor \& Fernald, 1997; Ivanovic, 1996; Ivanovic et al., 2000d, 2002; Leiva et al., 2001; Stoch et al., 1982; Winick \& Rosso, 1969a). Malnutrition alters brain development and intelligence in a multicausal context, and poverty and deprivation exacerbate these negative effects, especially when these factors persist throughout the lifetime of the individual. Under these conditions, a stable environment that provides adequate stimulation is very difficult to achieve and for this reason the brain damage caused by malnutrition at an early age frequently is not reversible (Brown \& Pollitt, 1996).

In a multifactorial approach, the aim of this study was to determine the interrelationships between the head size and intelligence, learning, nutritional status, brain development and parental head size in healthy Chilean school-age children graduating from high school, of both sexes, with high and low intellectual quotient and of the high and low socio-economic strata. The final purpose was to confirm the hypothesis that: (1) independently of age, sex and socio-economic strata, brain parameters, parental HC 
and prenatal nutritional indicators are the most important independent variables that determine $\mathrm{HC}$ and (2) microcephalic children present multiple disorders not only related to BV but also to IQ, SA and nutritional background, variables that are significantly interrelated.

\section{Methods}

\subsection{Participants}

The final sample consisted of 96 right-handed, healthy high school graduate students born at term (mean age 18.0土 0.9 years) who had no history of alcoholism, or symptoms of brain damage, intrapartum fetal asphyxia, hyperbilirubinemia, epilepsy, or heart disease and whose mothers had no history of smoking, alcoholism or drug intake before and during pregnancy. The sample was chosen from among 1817 school-age children, the total population graduating from high school who attended public and private schools in the richest and the poorest counties of the Chile's Metropolitan Region, according to the UNICEF classification (UNICEF, 1994). Intellectual quotient (Wechsler Intelligence Scale for Adults-Revised (WAIS-R)), socio-economic stratum and sex were considered for sample selection. A comparative study of two groups of Chilean high school graduates was carried out: group 1, high IQ ( $\geq 120$ WAIS-R) and group 2, low IQ $(<100$ WAIS-R). The total IQ of the school-age children from the group $1(125.4 \pm 5.5 ; n=47)$ was significantly higher than those from the group 2 (91.4 \pm 6.8 ; $n=49)(t=26.934 P<0.0001)$ and this was observed for both verbal and non-verbal IQ, as we reported previously (Ivanovic et al., 2002). IQ (total, verbal and non-verbal) did not differ by sex in both IQ levels and SES. The same proportion of school-age children according to SES (high and low) (1:1) and sex (1:1) were included in each IQ group (Ivanovic et al., 2002). This study was approved by the Committee on Ethics in Studies in Humans of the Institute of Nutrition and Food Technology (INTA), University of Chile. The subjects' consent was obtained according to the Declaration of Helsinki (The World Medical Association, 1964).

\subsection{SES}

SES was assessed applying the Graffar modified scale adapted for Chilean urban population that considers items such as schooling, job held by the head of the household, characteristics of the house (building materials, ownership status, water supply, sewerage and ownership of durable goods) (Alvarez, Muzzo, \& Ivanovic, 1985). The scale classifies a population into six socio-economic strata: (1) high; (2) medium-high; (3) medium; (4) medium-low; (5) low and (6) extreme poverty. In the present study, only high $(1+2)$ and low $(4+5+6)$ SES were considered because they represent extreme SES conditions.

\subsection{Nutritional status}

Nutritional status was assessed by means of measurements of weight $(W)$, height $(H)$, head circumference $(\mathrm{HC})$, arm circumference (AC) and triceps skinfold (TS) that were performed by the principal author using standardised procedures (Gibson, 1990). Weight-for-age $Z$-score $(Z-W)$ and height-for-age $Z$-score $(Z-H)$ were not calculated since most part of the sample was older than 18 years and WHO tables (WHO (1980) could not be applied. The body mass index, $W / H^{2}$ (BMI) was compared with the Garrow norms (Garrow, 1981).

HC was compared with the tables of Ivanovic et al. (1995), Nellhaus (1968), Roche, Mukherjee, Guo and Moore (1987) and Tanner (1984), by sex and age and was expressed as Z-score (Z-HC); in this respect, mean \pm 2 S.D. was considered "normal HC", $<-2$ S.D. microcephaly and $>2$ S.D. macrocephaly. Z-HC values were the same when applying the different tables because the correlation coefficient between these patterns was 0.98 (Ivanovic et al., 1995). In this study, HC values were compared with the tables of Roche et al. (1987) and were categorised as follows: $<-2,-2$ to $<0,0-2$ and $>2$ S.D., considering that, as we said previously, $\mathrm{HC}$ values immediately under the mean are associated with an increased incidence of lower intellectual ability (Ivanovic et al., 2000b).

Percentages of adequacy to the median of arm circumference-for-age ( $\%$ AC/A), triceps skinfold-for-age (\% $\mathrm{TS} / A$ ), arm muscle area-for-age ( $\%$ AMA $/ A$ ) and arm fat area-for-age (\% AFA/A) were calculated using data from Frisancho (1981). Birth weight (BW) and birth length (BL) were used as indexes of prenatal nutrition, Z-HC and \% AMA/A, served as indicators of postnatal nutrition and the BMI was used as an index of current nutritional status. These data were complemented with those obtained from the births register at the National Registry Office. Parents were interviewed to obtain information about the child's previous nutritional diseases, especially undernutrition at an early age.

\subsection{Study of brain development}

Brain development was evaluated at the German Clinic of Santiago by magnetic resonance imaging (MRI) according to standardised techniques (Willerman et al., 1991). Using the lowest margin of the cerebellum in a midsagittal view to align the first axial (horizontal) MRI slice, 18 mixed-weighted images (spin-echo pulse sequence with a TR of $2000 \mathrm{~ms}$ and a TE of $30 \mathrm{~ms}$ ) were obtained from a Signa MRI GE (General Electric Medical Systems, Milwaukee, Wisconsin, USA) unit with field strength of $1.5 \mathrm{~T}$. All slices were $5 \mathrm{~mm}$ thick and separated by $2.5 \mathrm{~mm}$. Each image was $256 \times 256$ pixels with 256 levels of gray. The MRI tape was read into a visual analog scale (VAS), computed and the image analysed after removing identifying information. A trained specialist without foreknowledge of either IQ or sex carried out the analyses. For each slice, a Roberts gradient 
traced the boundary of the scalp by outlining large-intensity differences between adjacent pixels. All gray scale intensity values of $<96$ within this boundary were converted to zero. This deleted the skull, most of the meninges, and the interhemispheric fissure; other brain membranes were deleted manually with a cursor. The computer then counted all pixels with nonzero gray scale values for brain size in each slice, their summed value serving as the index for overall brain size. Cortex thickness data, brain volume (BV), biparietal diameter (BD) and anteroposterior diameter (APD), corpus callosum (CC) length, thickness of genu (CCGT), body (CCBT) and splenium (CCST), the presence of neuronal migration disorders, qualitative and quantitative evaluation of white matter, cortical and basal subarachnoid space and ventricular system size are reported.

Some authors emphasise that, at present, there is no meaningful basis for the comparison of brain sizes within and between racial groups and sexes; the control for body size across racial groups (and sexes) is rendered difficult because bodies do not just differ only in $H$ and $W$ (Peters et al., 1998). In the present study, the correlations between $\mathrm{BV}$ and $H$ and $W$ were very low, as we informed in a previous report (Ivanovic et al., 2002) and the analysis of covariance (Guilford \& Fruchter, 1984) revealed that no significant effect of sex, $H$ and $W$ was observed for $\mathrm{BV}$; however, despite of this, values were adjusted by body size ( $W$ and $H$ ) but were so similar to absolute values that only these are reported in the present study. In the same way, CC length was adjusted for BV and CCGT, CCBT and CCST were adjusted for $\mathrm{CC}$ length using analysis of covariance (Frodl et al., 2001; Guilford, \& Fruchter, 1984; Matano \& Nakano, 1998), but adjusted values were so similar to absolute values that only these are reported.

\subsection{Intellectual quotient}

Obviously, human intelligence exceeds all that is measured by an IQ test score, but most studies have defined "intelligence" operationally as performance on IQ or similar tests. In this study, IQ (total, verbal and non-verbal) was assessed by means of the Wechsler Intelligence Scale for Adults-Revised adapted for Chilean population and was carried out at the school (Wechsler, 1981; Hermosilla, 1986). WAIS-R consists of a set of six verbal and five non-verbal subtests that are individually administered requiring about $1.5 \mathrm{~h}$, and yields an age-corrected estimate of IQ. To avoid examiner bias, the WAIS-R was administered separately to each child in quiet rooms by a team of educational psychologists specially trained in this type of study. Before each phase of the test, the psychologist provided a clear explanation to each child, in order to clarify the problem to be solved.

\subsection{Scholastic achievement test (SAT)}

SA was evaluated through standard Spanish language (LA) and mathematics (MA) tests especially designed for this study. Content validity was based on the fact that the test was designed taking into consideration the objectives pursued by the curricular programmes of the Chilean Ministry of Education (Chile Ministerio de Educación Pública, 1996). The items tested were 51 for LA and 65 for MA. A pilot test was carried out in 160 school-age children during which reliability was determined applying the Spearman-Brown correlation, scores being 0.92 and 0.97 for LA and MA, respectively, when comparing paired and unpaired items (Guilford \& Fruchter, 1984). Item-test consistency for each item was measured by Pearson correlation scoring values above 0.30 in all of them (Guilford \& Fruchter, 1984). Results were expressed as percentage of achievement in overall results $(\mathrm{SAT})(((\mathrm{LA}+\mathrm{MA}) / 116) \times 100)$, as well as LA $((\mathrm{LA} / 51)$ $\times 100)$ and MA $((\mathrm{LA} / 65) \times 100)$. Besides these tests, the academic aptitude test (AAT), the baccalaureate examination for university admission with national coverage, was also considered, both verbal (90 items) and mathematics (60 items) tests, with a maximum score of 900 in each test. The overall results in the AAT were also calculated (verbal + mathematics)/2.

\subsection{Statistical analysis}

Data were analysed by means of covariance tests, variance tests, Scheffe's test for comparison of means, correlation, multiple regression and chi-square test $\left(\chi^{2}\right)$ that was used to determine significant differences between the categorical variables using the Statistical Analysis System (SAS) package (Guilford \& Fruchter, 1984; SAS, 1983).

\section{Results}

\subsection{Distribution of the sample of Chilean high school graduates by Z-HC categories and total IQ group}

As regards to Z-HC, 5.2 and $3.1 \%$ of the sample registered values $<-2$ S.D. (microcephaly) and $>2$ S.D. (macrocephaly), respectively. Most of the sample, 91.7\%, had a "normal HC" (mean \pm 2 S.D.); however 57.3\% exhibited Z-HC values between -2 to $<0$ S.D. and $34.4 \%$, between 0 and 2 S.D., without significant differences by sex.

The distribution of the sample by Z-HC categories and total IQ group is shown in Fig. 1. Considering that children were paired by SES in each IQ group, it can be observed that all students with $Z$-HC values $<-2$ and $>2$ S.D. had low and high IQ, respectively. Although the category -2 to $<0$ S.D. falls within the "normal" range for $\mathrm{HC}$, the percentage of children with low IQ $(60.0 \%)$ increases significantly compared with their peers with high IQ (40\%). The opposite is observed in the category 0-2 S.D. (33.3 and 66.7\%, respectively) $(P<0.01)$. This was observed both males and females. 


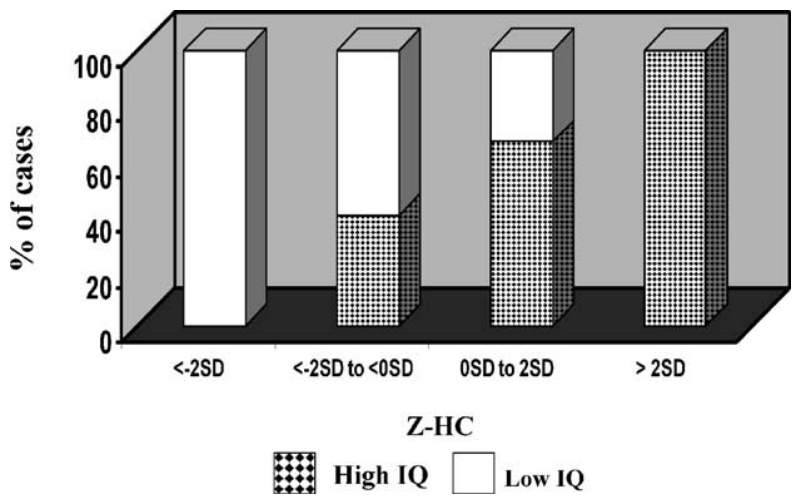

Fig. 1. Distribution of the sample of Chilean high school graduates by head circumference-for-age $Z$-score $(Z$-HC) categories and total intellectual quotient (IQ) group. $\chi_{\mathrm{o}}^{2}(1)=9.674>\chi_{\mathrm{t}}^{2}(1) 0.01=6.635$. Chi-square was calculated comparing $Z$-HC values $<0$ and $\geq 0$ S.D.

\subsection{Mean age, IQ, SA and AAT score by Z-HC categories}

Table 1 summarises the mean \pm S.D. of age, IQ, SA and AAT score by Z-HC categories. School-age children of both sexes with $Z$-HC values $<-2$ S.D. were significantly older compared with their peers with values between 0 and 2 S.D. and $>2$ S.D. $(P<0.01)$. In fact, the group with $Z-H C$ values $<-2$ S.D. were 1.5 years older than those with the greatest $Z$-HC values. The mean total IQ in school-age children with $Z$-HC values $<-2$ S.D. was 33 points lower than those with values $>2$ S.D. $(P<0.01)$. In verbal and non-verbal IQ, this difference was 40.9 points $(P<0.001)$ and 17.9 points $(P<0.05)$, respectively and the same was observed in both sexes. Total, verbal and nonverbal IQ values were similar within -2 to $<0$ S.D. group and within 0-2 S.D. group, although values were significantly higher in this latter group. School-age children with $Z$-HC values $<-2$ S.D. attained significantly lower percentages of correct responses in the SAT (8.6\%), in comparison with their peers whose $Z$-HC values were between 0 and 2 S.D. (56.6\%) and $>2$ S.D. $(78.8 \%)(P<0.01)$. This was also observed in both sexes for both LA $(P<0.001)$ and MA $(P<0.05)$. Thus, in both sexes, performance in the SAT was very low in school-age children with $Z$-HC values $<-2$ S.D. of whom 80 and $20 \%$ presented SAT scores $<25 \%$ and between 25 and $49 \%$ of correct responses, respectively. None of the subjects in this group scored $\geq 50 \%$ of correct responses. On the contrary, in the group with Z-HC values >2 S.D., 33.3 and $66.7 \%$ achieved between 50 and $74 \%$ and $\geq 75 \%$ of correct responses, respectively and none of them presented scores $<50 \%$. In the total mean AAT, school-age children with $Z$-HC values $<-2$ S.D., both males and females, scored significantly lower than their peers from the other groups of the sample $(P<0.01)$. In fact, school-age children with $Z$-HC values $<-2$ and $>2$ S.D. scored $44.8 \%$ versus $82.8 \%$ of achievement in the total mean AAT, respectively. Verbal and mathematics AAT scores exhibited similar results with respect to the mean total AAT. All children with Z-HC values $<-2$ S.D. registered AAT scores $<$ p25 ( $<450$ points) and in the $>2$ S.D. group, $33.3 \%$ scored between p50 and $<$ p75 (631-736 points) and most of them, $66.7 \%$, scored $\geq$ p75 ( $\geq 737$ points).

\subsection{Nutritional parameters by Z-HC categories}

Nutritional parameters by Z-HC categories are described in Table 2. School-age children of both sexes with Z-HC

Table 1

Age, intellectual quotient (IQ), scholastic achievement (SA) and academic aptitude test (AAT) score of Chilean high school graduates by head circumference-for-age $Z$-score $(Z-H C)$ categories ${ }^{\mathrm{a}}$

\begin{tabular}{|c|c|c|c|c|c|}
\hline & \multicolumn{4}{|l|}{ Z-HC } & \multirow[t]{2}{*}{$F$} \\
\hline & $<-2$ S.D. (5) & -2 to $<0$ S.D. (55) & 0-2 S.D. (33) & $>2$ S.D. (3) & \\
\hline Age (years) & $18.9 \mathrm{a} \pm 0.3$ & $18.1 \mathrm{ab} \pm 1.0$ & $17.7 b \pm 0.5$ & $17.4 \mathrm{~b} \pm 0.4$ & $4.20^{* *}$ \\
\hline \multicolumn{6}{|l|}{ IQ (score) } \\
\hline Total & $91.0 \mathrm{a} \pm 7.3$ & $104.3 \mathrm{a} \pm 17.9$ & $115.4 \mathrm{~b} \pm 16.6$ & $124.0 \mathrm{~b} \pm 5.3$ & $5.50^{* *}$ \\
\hline Verbal & $87.8 \mathrm{a} \pm 5.7$ & $104.2 \mathrm{ab} \pm 18.5$ & $114.8 \mathrm{~b} \pm 16.6$ & $128.7 b \pm 2.1$ & $6.30^{* * *}$ \\
\hline Non-verbal & $96.4 \mathrm{a} \pm 9.8$ & $104.2 \mathrm{ab} \pm 16.2$ & $113.9 \mathrm{~b} \pm 15.8$ & $114.3 b \pm 13.7$ & $3.61^{*}$ \\
\hline \multicolumn{6}{|c|}{ SA ( $\%$ of correct responses) } \\
\hline Overall results & $8.6 \mathrm{a} \pm 9.2$ & $46.6 \mathrm{ab} \pm 26.9$ & $56.6 b \pm 26.6$ & $78.8 \mathrm{~b} \pm 12.1$ & $4.53^{* *}$ \\
\hline LA & $29.0 \mathrm{a} \pm 12.9$ & $51.8 \mathrm{ab} \pm 22.9$ & $60.5 \mathrm{ab} \pm 25.1$ & $81.7 \mathrm{~b} \pm 11.8$ & $4.26^{* * *}$ \\
\hline MA & $11.5 \mathrm{a} \pm 9.5$ & $43.1 \mathrm{ab} \pm 32.3$ & $52.8 \mathrm{ab} \pm 32.7$ & $76.8 b \pm 12.9$ & $3.51^{*}$ \\
\hline AAT (score) & (2) & $(48)$ & $(31)$ & (3) & \\
\hline Overall results & $403.3 \mathrm{a} \pm 42.7$ & $545.0 \mathrm{~b} \pm 158.1$ & $643.7 b c \pm 145.6$ & $744.8 \mathrm{c} \pm 39.5$ & $4.79^{* *}$ \\
\hline Verbal AAT & $383.5 \mathrm{a} \pm 61.5$ & $521.9 \mathrm{a} \pm 153.3$ & $637.6 \mathrm{~b} \pm 152.0$ & $719.7 b \pm 38.1$ & $5.76^{* *}$ \\
\hline Mathematics AAT & $423.0 \mathrm{a} \pm 19.8$ & $568.2 \mathrm{ab} \pm 169.8$ & $649.9 b \pm 148.6$ & $770.0 \mathrm{~b} \pm 42.6$ & $3.62^{*}$ \\
\hline
\end{tabular}

${ }^{a}$ Results are expressed as mean \pm S.D. The number of cases is indicated between parentheses. Means with the same letter are not significantly different at the 0.05 level based on Scheffe's test. F, ANOVA; LA, Spanish language achievement; MA, mathematics achievement.

$* P<0.05$.

** $P<0.01$.

*** $P<0.001$. 
Table 2

Nutritional parameters of Chilean high school graduates by head circumference-for-age Z-score $\left(Z\right.$-HC) categories ${ }^{\mathrm{a}}$

\begin{tabular}{|c|c|c|c|c|c|}
\hline \multirow[t]{2}{*}{ Nutritional parameters } & \multicolumn{4}{|l|}{ Z-HC } & \multirow[t]{2}{*}{$F$} \\
\hline & $<-2$ S.D. (5) & -2 to $<0$ S.D. $(55)$ & 0-2 S.D. (33) & $>2$ S.D. (3) & \\
\hline \multicolumn{6}{|c|}{ Prenatal nutritional background } \\
\hline BW (g) & $2750.0 \pm 316.2$ & $3062.1 \pm 495.2$ & $3170.3 \pm 658.2$ & $3716.7 \pm 332.9$ & $2.25(\mathrm{t})$ \\
\hline $\mathrm{BL}(\mathrm{cm})$ & $46.0 \mathrm{a} \pm 4.5$ & $48.9 \mathrm{ab} \pm 2.8$ & $49.6 \mathrm{ab} \pm 2.9$ & $51.3 b \pm 1.2$ & $2.82^{*}$ \\
\hline \multicolumn{6}{|c|}{ Postnatal nutritional background } \\
\hline \multicolumn{6}{|l|}{ Body $W(\mathrm{~kg})$} \\
\hline Males & $48.4 \mathrm{a} \pm 2.2$ & $65.3 b \pm 9.4(24)$ & $66.9 \mathrm{~b} \pm 4.9(18)$ & $73.8 b \pm 1.4(2)$ & $6.16^{* *}$ \\
\hline Females & $47.5 \pm 3.6(2)$ & $55.8 \pm 6.9(31)$ & $60.2 \pm 11.3(15)$ & $63.5 \pm 0.0$ & 1.95 \\
\hline \multicolumn{6}{|l|}{ Body $H(\mathrm{~cm})$} \\
\hline Males & $166.0 \pm 8.6(3)$ & $170.7 \pm 6.2(24)$ & $171.6 \pm 6.2(18)$ & $176.0 \pm 3.5(2)$ & 1.15 \\
\hline Females & $156.9 \mathrm{ab} \pm 7.6(2)$ & $157.6 \mathrm{a} \pm 5.0(31)$ & $163.3 b \pm 6.8(15)$ & $160.6 \mathrm{ab} \pm 0.0$ & $3.54 *$ \\
\hline \multicolumn{6}{|l|}{$\mathrm{HC}(\mathrm{cm})$} \\
\hline Males & $51.7 \mathrm{a} \pm 0.9$ & $54.9 \mathrm{~b} \pm 0.6(24)$ & $56.8 \mathrm{c} \pm 0.7(18)$ & $59.7 \mathrm{~d} \pm 0.3(2)$ & $90.72^{* * * *}$ \\
\hline Females & $51.9 \mathrm{a} \pm 0.4(2)$ & $53.9 \mathrm{~b} \pm 0.6(31)$ & $55.6 \mathrm{c} \pm 0.8(15)$ & $57.5 \mathrm{c} \pm 0.0(1)$ & $41.20^{* * * *}$ \\
\hline \multicolumn{6}{|l|}{$\mathrm{Z}-\mathrm{HC}$} \\
\hline Males & $-3.17 \mathrm{a} \pm 0.64$ & $-0.67 b \pm 0.48(24)$ & $0.78 \mathrm{c} \pm 0.53$ & $2.98 \mathrm{~d} \pm 0.21$ & $91.65^{* * * *}$ \\
\hline Females & $-2.63 \mathrm{a} \pm 0.30(2)$ & $-0.68 b \pm 0.45(31)$ & $0.57 \mathrm{c} \pm 0.54(18)$ & $2.01 \mathrm{c} \pm 0.00(1)$ & $46.21^{* * * *}$ \\
\hline \multicolumn{6}{|l|}{ Current nutritional status } \\
\hline $\mathrm{BMI}\left(P / T^{2}\right)$ & $18.3 \mathrm{a} \pm 1.2$ & $22.4 b \pm 2.7$ & $22.7 b \pm 3.4$ & $24.1 b \pm 1.1$ & $3.97^{*}$ \\
\hline \multicolumn{6}{|c|}{ Brachial anthropometric parameters } \\
\hline$\% \mathrm{AC} / A$ & $79.7 \mathrm{a} \pm 10.8$ & $96.4 b \pm 11.3$ & $98.5 b \pm 11.9$ & $101.4 \mathrm{~b} \pm 4.5$ & $4.14^{* *}$ \\
\hline$\% \mathrm{TS} / A$ & $72.8 \pm 24.2$ & $111.6 \pm 42.0$ & $119.3 \pm 59.3$ & $120.8 \pm 34.7$ & 1.39 \\
\hline$\%$ AMA $/ A$ & $67.2 \mathrm{a} \pm 17.0$ & $90.3 \mathrm{ab} \pm 16.9$ & $95.3 b \pm 22.7$ & $103.1 b \pm 16.0$ & $3.57^{*}$ \\
\hline$\%$ AFA $/ A$ & $60.1 \pm 24.3$ & $110.2 \pm 48.7$ & $118.5 \pm 63.0$ & $122.2 \pm 28.0$ & 1.80 \\
\hline
\end{tabular}

${ }^{a}$ Results are expressed as mean \pm S.D. The number of cases is indicated between parentheses. Means with the same letter are not significantly different at the 0.05 level based on Scheffe's test. $F$, ANOVA; BW, birth weight; BL, birth length; $W$, weight; $H$, height; BMI, body mass index; AC/A, arm circumference-for-age; TS/A, triceps skinfold-for-age; AMA/A, arm muscle area-for-age; AFA/A, arm fat area-for-age.

$* P<0.05$.

** $P<0.01$

**** $P<0.0001 ;(\mathrm{t})$, tendency $(P<0.0927)$.

values $<-2$ S.D. had prenatal nutritional parameters such as BW $(P>0.05$ and $<0.1)$ and BL $(P<0.05)$ representing approximately $1000 \mathrm{~g}$ and $5 \mathrm{~cm}$ less than the $>2$ S.D. group, respectively. In children with $Z$-HC values $<-2$ S.D., $20 \%$ had low BW $(1.500$ to $<2.500 \mathrm{~g}), 60 \%$ showed insufficient BW $(2.500-2.999 \mathrm{~g})$ and only $20 \%$, showed values in the range of 3.000-3.499 g. In the group with Z-HC values $>2$ S.D., 33.3 and $66.7 \%$ weighted between 3.000 and $3.499 \mathrm{~g}$ and $\geq 3.500 \mathrm{~g}$ at birth, respectively. In relation to BL, all the children with $Z$-HC values $<-2$ S.D. had a length at birth $<50 \mathrm{~cm}$ (40 and $60 \%$ presented BL values $<48 \mathrm{~cm}$ and between 48 and $49 \mathrm{~cm}$, respectively). The opposite was observed in the $>2$ S.D. group (33.3 and $66.7 \%$ registered BL values between 50 and $51 \mathrm{~cm}$ and $\geq 52 \mathrm{~cm}$, respectively). As regards present body $W$, values were significantly lower in males with $Z$-HC values $<-2$ S.D. compared with the other groups $(P<0.01)$. In females, despite the fact that $W$ values were lower in those with $Z$-HC values $<-2$ S.D., differences were not significant. Present body $H$ was lower in females with $Z$-HC values $<-2$ S.D. $(P<0.05)$ and, in males, $H$ did not differ significantly between $Z$-HC groups although children with $Z$-HC values $<-2$ S.D. had a lower $H$ com- pared with the rest of the sample. Differences between HC values $(\mathrm{cm})$ expressed by $Z$-HC categories are obvious since the sample was distributed on this basis. However, it is necessary to underline that in males, $\mathrm{HC}$ values of school-age children with $Z$-HC values $<-2$ S.D. were $8 \mathrm{~cm}$ lower than those with values $>2$ S.D.; in females, this difference was $5.6 \mathrm{~cm}(P<0.0001)$. BMI $(P<0.05), \%$ AC/A $(P<0.01)$ and $\% \mathrm{AMA} / A(P<0.05)$ values were significantly lower in school-age children of the $<-2$ S.D. group. Antecedents related to postnatal nutrition revealed that $16.6 \%$ of the sample had suffered from undernutrition in the first year of life and that all of them belonged to low SES. Most children with $Z$-HC values $<-2$ S.D. (60\%) had suffered undernutrition during the first year of life, a percentage that decreased significantly to 20 and $6 \%$, in the groups with $Z$-HC values between -2 and $<0$ S.D. and $0-2$ S.D., respectively $(P<$ 0.05) (Fig. 2).

\subsection{Parental HC by child's Z-HC categories}

Table 3 shows parental HC by child's Z-HC categories. Paternal and maternal absolute $\mathrm{HC}$ and $Z$-HC values were 


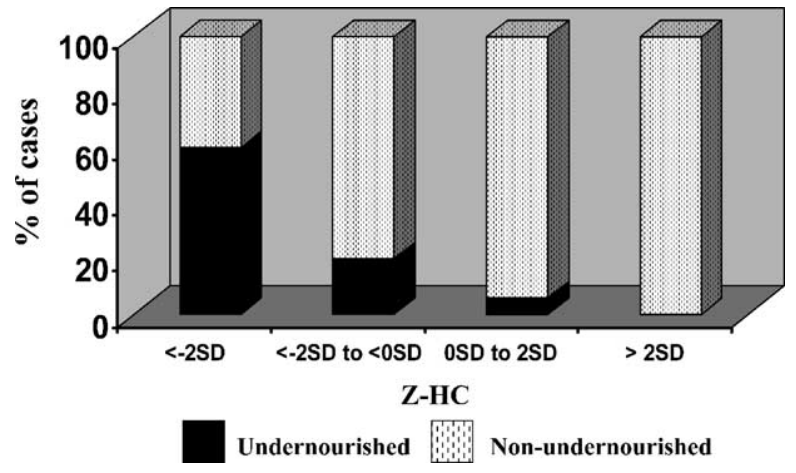

Fig. 2. Distribution of the sample of Chilean high school graduates with and without undernutrition in the first year of life by head circumference-for-age $Z$-score $(Z-H C)$ categories. $\chi_{\mathrm{o}}^{2}(1)=5.120>$ $\chi_{\mathrm{t}}^{2}(1) 0.05=3.841$. Chi-square was calculated comparing $Z$-HC values $<0$ and $\geq 0$ S.D.

significantly lower in children with $Z$-HC values $<-2$ S.D. compared with their peers from 0 to 2 S.D. and $>2$ S.D. groups. Paternal and maternal Z-HC values were 2.83 and 1.76 points lower in children with $Z$-HC values $<-2$ S.D. compared with >2 S.D. group, respectively.

\subsection{Absolute parameters of brain development distributed by Z-HC categories and sex}

Table 4 outlines brain development parameters according to $Z$-HC categories and sex. Males with $Z$-HC values $<-2$ S.D. registered a $C C$ length significantly lower than the $0-2$ S.D. group $(P<0.05)$, an absolute BV significantly lower than their peers of the other groups of the sample $(P<$ $0.0001)$ and a APD significantly lower than their peers of the $0-2$ S.D. and $>2$ S.D. groups $(P<0.0001)$. As a consequence, the $<-2$ S.D. group had a BV $449.1 \mathrm{~cm}^{3}$ lower than the $>2$ S.D. group, while among the females this difference was $214.4 \mathrm{~cm}^{3}(P<0.001)$. In males, APD was $13.2 \mathrm{~mm}$ smaller in the $<-2$ S.D. group compared with their peers of the $>2$ S.D. group $(P<0.0001)$ while in the females this dif- ference was $18.5 \mathrm{~mm}(P<0.01)$. CCGT, CCBT and CCST values were not significantly different when evaluated in relation to Z-HC in both males and females. Mean cortex thickness in the frontal, parietal, temporal and occipital lobules was near $4 \mathrm{~mm}$ in all $\mathrm{Z}$-HC categories. Abnormal amounts of white matter were detected in two children, five manifested an abnormally large subarachnoid space and ventricular system size and six of them had an encephalic parenchyma abnormal by MRI without significant association with Z-HC categories.

\subsection{Children $B V$ and $H C$ of the children and their parents by total IQ group, SES and sex}

Children BV, absolute HC and expressed as Z-HC both in children and their parents by total IQ group, SES and sex is indicated in Table 5. Within each IQ group no significant difference was observed according to SES and sex for BV, $\mathrm{HC}$ and $\mathrm{Z}-\mathrm{HC}$ of the children and for $\mathrm{HC}$ and $\mathrm{Z}-\mathrm{HC}$ of the parents.

\subsection{Interrelationship between most relevant parameters}

Table 6 shows the Pearson correlation coefficients for the most relevant parameters. A high correlation was observed between $Z$-HC and absolute BV $(r=0.841 P<0.0001)$. $Z$-HC and BV were also positively and significantly correlated with parental $\mathrm{HC}, \mathrm{BW}, \mathrm{BL}, \mathrm{IQ}, \mathrm{SA}$ and AAT and negatively with severe undernutrition in the first years of life and age. All these variables were significantly interrelated. It should be noted that with the exception of undernutrition in the first year of life, age was negatively and significantly correlated with all these variables. SES positively and significantly correlated with paternal $\mathrm{HC}$ and $\mathrm{BL}$ and negatively with severe undernutrition in the first year of life. No significant correlation was observed between $\mathrm{BMI}, \mathrm{AC} / \mathrm{A}$ or $\mathrm{AMA} / \mathrm{A}$ with $\mathrm{BW}, \mathrm{BL}, \mathrm{IQ}, \mathrm{SA}$ and AAT.

Table 3

Parental head circumference (HC) by school-age children's HC-for-age Z-score (Z-HC) categories ${ }^{\mathrm{a}}$

\begin{tabular}{|c|c|c|c|c|c|}
\hline \multirow[t]{2}{*}{ Parental HC } & \multicolumn{4}{|l|}{ Z-HC } & \multirow[t]{2}{*}{$F$} \\
\hline & $<-2$ S.D. (5) & -2 to $<0$ S.D. (55) & 0-2 S.D. (33) & $>2$ S.D. (3) & \\
\hline \multicolumn{6}{|l|}{ Paternal } \\
\hline Absolute PHC (cm) & $54.1 \mathrm{a} \pm 1.5$ & $56.0 \mathrm{ab} \pm 1.3$ & $56.6 \mathrm{~b} \pm 1.0$ & $57.9 \mathrm{~b} \pm 1.0$ & $6.54^{* * *}$ \\
\hline Z-PHC & $-1.38 \mathrm{a} \pm 1.15$ & $0.00 \mathrm{ab} \pm 0.95$ & $0.50 \mathrm{~b} \pm 0.78$ & $1.45 \mathrm{~b} \pm 0.71$ & $6.51^{* * *}$ \\
\hline \multicolumn{6}{|l|}{ Maternal } \\
\hline Absolute MHC (cm) & $52.8 \mathrm{a} \pm 1.5$ & $53.7 \mathrm{ab} \pm 1.5$ & $54.6 \mathrm{~b} \pm 1.1$ & $55.2 \mathrm{~b} \pm 0.9$ & $4.15^{* *}$ \\
\hline Z-MHC & $-1.55 \mathrm{a} \pm 1.07$ & $-0.87 a b \pm 1.09$ & $-0.26 b \pm 0.80$ & $0.21 b \pm 0.67$ & $4.14^{* *}$ \\
\hline
\end{tabular}

${ }^{a}$ Results are expressed as mean \pm S.D. The number of cases is indicated between parentheses. Means with the same letter are not significantly different at the 0.05 level based on Scheffe's test. F, ANOVA; PHC, paternal head circumference; Z-PHC, paternal head circumference-for-age Z-score; MHC, maternal head circumference; Z-MHC, maternal head circumference-for-age Z-score.

** $P<0.01$.

*** $P<0.001$. 
Table 4

Absolute brain development parameters of Chilean high school graduates by head circumference-for-age $Z$-score $\left(Z\right.$-HC) categories and sex ${ }^{a}$

\begin{tabular}{|c|c|c|c|c|c|}
\hline \multirow[t]{2}{*}{ Absolute brain parameters } & \multicolumn{4}{|l|}{$\mathrm{Z}-\mathrm{HC}$} & \multirow[t]{2}{*}{$F$} \\
\hline & $<-2$ S.D. & -2 to $<0$ S.D. & 0-2 S.D. & $>2$ S.D. & \\
\hline Males & (3) & (24) & (18) & (2) & \\
\hline CC Length (mm) & $64.7 \mathrm{a} \pm 4.0$ & $70.9 \mathrm{ab} \pm 4.4$ & $73.4 b \pm 4.5$ & $72.0 \mathrm{ab} \pm 2.8$ & $3.66^{*}$ \\
\hline CCGT (mm) & $10.3 \pm 2.01$ & $11.1 \pm 1.5$ & $11.9 \pm 1.8$ & $11.0 \pm 1.4$ & 1.14 \\
\hline CCBT (mm) & $6.0 \pm 1.0$ & $6.1 \pm 1.0$ & $6.4 \pm 0.7$ & $5.5 \pm 0.7$ & 1.03 \\
\hline $\operatorname{CCST}(\mathrm{mm})$ & $10.0 \pm 2.0$ & $11.4 \pm 1.3$ & $11.7 \pm 1.8$ & $10.0 \pm 0.0$ & 1.68 \\
\hline $\mathrm{BV}\left(\mathrm{cm}^{3}\right)$ & $1208.6 \mathrm{a} \pm 139.2$ & $1432.9 b \pm 87.4$ & $1568.9 \mathrm{c} \pm 41.2$ & $1657.7 \mathrm{c} \pm 7.7$ & $28.25^{* * * *}$ \\
\hline $\mathrm{BD}(\mathrm{mm})$ & $128.3 \pm 1.5$ & $132.3 \pm 7.0$ & $133.0 \pm 6.9$ & $136.5 \pm 2.1$ & 0.67 \\
\hline $\mathrm{APD}(\mathrm{mm})$ & $156.3 \mathrm{a} \pm 10.1$ & $161.9 \mathrm{a} \pm 5.3$ & $169.1 b \pm 4.4$ & $169.5 b \pm 6.4$ & $9.24^{* * * *}$ \\
\hline Females & $(2)$ & $(31)$ & $(15)$ & (1) & \\
\hline CC Length (mm) & $69.0 \pm 0.0$ & $70.5 \pm 4.6$ & $71.1 \pm 5.5$ & $79.0 \pm 0.0$ & 1.11 \\
\hline CCGT (mm) & $12.0 \pm 0.0$ & $10.8 \pm 1.7$ & $10.9 \pm 1.5$ & $13.0 \pm 0.0$ & 0.96 \\
\hline CCBT (mm) & $6.0 \pm 0.7$ & $6.4 \pm 0.8$ & $6.7 \pm 0.9$ & $6.0 \pm 0.0$ & 0.49 \\
\hline CCST (mm) & $10.5 \pm 2.1$ & $11.2 \pm 1.5$ & $11.6 \pm 1.7$ & $13.0 \pm 0.0$ & 0.75 \\
\hline $\mathrm{BV}\left(\mathrm{cm}^{3}\right)$ & $1252.9 \mathrm{a} \pm 98.7$ & $1370.8 \mathrm{a} \pm 77.5$ & $1457.2 b \pm 69.3$ & $1467.3 b \pm 0.0$ & $7.11^{* * *}$ \\
\hline $\mathrm{BD}(\mathrm{mm})$ & $126.0 \pm 7.1$ & $128.9 \pm 6.5$ & $131.3 \pm 5.5$ & $137.0 \pm 0.0$ & 1.19 \\
\hline APD (mm) & $155.5 \mathrm{a} \pm 0.7$ & $160.3 \mathrm{ab} \pm 4.5$ & $164.7 \mathrm{ab} \pm 6.0$ & $174.0 \mathrm{~b} \pm 0.0$ & $5.74^{* *}$ \\
\hline
\end{tabular}

${ }^{a}$ Results are expressed as mean \pm S.D. The number of cases is indicated between parentheses. Means with the same letter are not significantly different at the 0.05 level based on Scheffe's test. F, ANOVA; CC, corpus callosum; CCGT, genu thickness; CCBT, body thickness; CCST, splenium thickness; BV, brain volume; BD, biparietal diameter; APD, anteroposterior diameter.

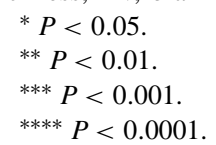

\subsection{Multiple regression analysis between children's Z-HC and most relevant parameters}

Multiple regression analysis between children's Z-HC (dependent variable) and age, sex, SES, BV (absolute or adjusted), paternal and maternal $\mathrm{HC}, \mathrm{BL}, \mathrm{BW}$ and undernutri- tion in the first year of life (independent variables) (Table 7) confirms that absolute BV (or adjusted) $(P<0.0001)$, paternal HC $(P<0.0116)$, maternal HC $(P<0.0200)$ and BL $(P<0.0364)$ were the independent variables with the greatest explanatory power for children's Z-HC variance $\left(r^{2}=0.727\right)$ without interaction with age, sex or SES.

Table 5

Comparison between brain volume (BV) in children and head circumference (HC) of both children and their parents within each total intellectual quotient (IQ) group by socio-economic stratum (SES) and $\operatorname{sex}^{\mathrm{a}}$

\begin{tabular}{|c|c|c|c|c|c|c|}
\hline & \multicolumn{2}{|l|}{ High total IQ } & \multirow[t]{2}{*}{ Student's “ $t$ "-test } & \multicolumn{2}{|l|}{ Low total IQ } & \multirow[t]{2}{*}{ Student's " $t$ "-test } \\
\hline & High SES & Low SES & & High SES & Low SES & \\
\hline \multicolumn{7}{|l|}{ High school graduates } \\
\hline Males $(n=47)$ & (12) & (11) & & (12) & (12) & \\
\hline Absolute $\mathrm{BV}\left(\mathrm{cm}^{3}\right)$ & $1551.6 \pm 63.7$ & $1544.5 \pm 109.7$ & $0.187 \mathrm{NS}$ & $1420.9 \pm 122.6$ & $1409.5 \pm 129.3$ & $0.222 \mathrm{NS}$ \\
\hline Absolute $\mathrm{HC}(\mathrm{cm})$ & $56.6 \pm 1.4$ & $56.4 \pm 1.5$ & $0.232 \mathrm{NS}$ & $55.5 \pm 1.5$ & $54.6 \pm 1.7$ & $0.677 \mathrm{NS}$ \\
\hline Z-HC & $0.59 \pm 1.04$ & $0.54 \pm 1.12$ & $0.100 \mathrm{NS}$ & $-0.61 \pm 1.17$ & $-0.94 \pm 1.29$ & $0.652 \mathrm{NS}$ \\
\hline Females $(n=49)$ & (12) & (11) & & (12) & (12) & \\
\hline Absolute $\mathrm{BV}\left(\mathrm{cm}^{3}\right)$ & $1434.2 \pm 86.7$ & $1403.4 \pm 99.1$ & $0.809 \mathrm{NS}$ & $1381.2 \pm 96.8$ & $1361.4 \pm 64.0$ & $0.600 \mathrm{NS}$ \\
\hline Absolute $\mathrm{HC}(\mathrm{cm})$ & $55.1 \pm 1.1$ & $54.5 \pm 1.2$ & $1.258 \mathrm{NS}$ & $54.5 \pm 1.2$ & $53.7 \pm 1.0$ & $1.692 \mathrm{NS}$ \\
\hline Z-HC & $0.19 \pm 0.80$ & $-0.20 \pm 0.87$ & $0.151 \mathrm{NS}$ & $-0.34 \pm 1.07$ & $-0.89 \pm 0.76$ & $1.445 \mathrm{NS}$ \\
\hline \multicolumn{7}{|l|}{ Parents } \\
\hline Absolute PHC (cm) & $56.8 \pm 1.2$ & $56.2 \pm 1.2$ & $1.515 \mathrm{NS}$ & $56.4 \pm 1.5$ & $55.4 \pm 1.4$ & $1.678 \mathrm{NS}$ \\
\hline Z-PHC & $0.63 \pm 0.86$ & $0.20 \pm 0.88$ & $1.517 \mathrm{NS}$ & $0.34 \pm 1.10$ & $-0.37 \pm 1.00$ & $1.676 \mathrm{NS}$ \\
\hline Absolute MHC (cm) & $54.2 \pm 1.4$ & $54.1 \pm 0.9$ & $0.319 \mathrm{NS}$ & $53.8 \pm 1.5$ & $54.0 \pm 1.9$ & $0.484 \mathrm{NS}$ \\
\hline Z-MHC & $-0.52 \pm 1.02$ & $-0.61 \pm 0.67$ & $0.313 \mathrm{NS}$ & $-0.84 \pm 1.05$ & $-0.67 \pm 1.35$ & $0.482 \mathrm{NS}$ \\
\hline
\end{tabular}

\footnotetext{
${ }^{a}$ Results are expressed as mean \pm S.D. The number of cases is indicated between parentheses. Z-HC, school-age children's head circumference-for-age $Z$-score; PHC, paternal head circumference; Z-PHC, paternal head circumference-for-age Z-score; MHC, maternal head circumference; Z-MHC, maternal head circumference-for-age $Z$-score; NS, not significantly different.
} 
Table 6

Correlation matrix. Pearson correlation coefficients for the most relevant parameters ${ }^{\mathrm{a}}$

\begin{tabular}{|c|c|c|c|c|c|c|c|c|c|c|c|c|}
\hline & Z-HC & $\mathrm{BV}$ & Z-PHC & Z-MHC & BW & $\mathrm{BL}$ & $\mathrm{UN}$ & IQ & SA & AAT & AGE & SES \\
\hline Z-HC & - & & & & & & & & & & & \\
\hline BV & $0.841^{* * * *}$ & - & & & & & & & & & & \\
\hline Z-PHC & $0.546^{* * * *}$ & $0.415^{* * *}$ & - & & & & & & & & & \\
\hline Z-MHC & $0.407^{* * * *}$ & $0.290^{* *}$ & $0.120 \mathrm{NS}$ & - & & & & & & & & \\
\hline BW & $0.289^{* *}$ & $0.229^{*}$ & $0.278^{*}$ & $0.034 \mathrm{NS}$ & - & & & & & & & \\
\hline BL & $0.325^{* *}$ & $0.256^{*}$ & $0.200 \mathrm{NS}$ & $0.011 \mathrm{NS}$ & $0.646^{* * * * *}$ & - & & & & & & \\
\hline UN & $-0.370^{* * *}$ & $-0.327^{* *}$ & $-0.338^{* *}$ & $-0.163 \mathrm{NS}$ & $-0.390^{* * * *}$ & $-0.476^{* * * *}$ & - & & & & & \\
\hline IQ & $0.465^{* * * *}$ & $0.436^{* * * *}$ & $0.292^{*}$ & $0.121 \mathrm{NS}$ & $0.258^{*}$ & $0.287^{*}$ & $-0.557^{* * * *}$ & - & & & & \\
\hline SA & $0.450^{* * * * *}$ & $0.451^{* * * *}$ & $0.330^{* *}$ & $0.097 \mathrm{NS}$ & $0.367^{* * *}$ & $0.354^{*}$ & $-0.469^{* * * *}$ & $0.893^{* * * *}$ & - & & & \\
\hline AAT & $0.434^{* * * *}$ & $0.321^{* *}$ & $0.225(t)$ & $0.108 \mathrm{NS}$ & $0.189(\mathrm{t})$ & $0.228(\mathrm{t})$ & $-0.419^{* * * *}$ & $0.923^{* * * *}$ & $0.925^{* * * *}$ & - & & \\
\hline AGE & $-0.342^{* * *}$ & $-0.282^{* *}$ & $-0.346^{* * *}$ & $-0.013 \mathrm{NS}$ & $-0.252^{*}$ & $-0.414^{* * *}$ & $0.454^{* * * *}$ & $-0.490^{* * * *}$ & $-0.563^{* * * *}$ & $-0.422^{* * * *}$ & - & \\
\hline SES & $0.158 \mathrm{NS}$ & $0.091 \mathrm{NS}$ & $0.297^{*}$ & $0.021 \mathrm{NS}$ & $0.188(\mathrm{t})$ & $0.234^{*}$ & $-0.447^{* * * *}$ & $0.155 \mathrm{NS}$ & $0.001 \mathrm{NS}$ & $0.012 \mathrm{NS}$ & $0.074 \mathrm{NS}$ & - \\
\hline
\end{tabular}

${ }^{a} Z$-HC, school-age children's head circumference-for-age Z-score; BV, brain volume; Z-PHC, paternal head circumference-for-age Z-score; Z-MHC, maternal head circumference-for-age Z-score; BW, birth weight; BL, birth length; UN, severe undernutrition in the first year of life; IQ, intellectual quotient; SA, scholastic achievement; AAT, academic aptitude test; SES, socio-economic stratum. (t) $=$ tendency $(P>0.05$ and $<0.10)$; NS, not significantly different.

$$
\begin{aligned}
& { }^{*} P<0.05 . \\
& { }^{* *} P<0.01 . \\
& { }^{* * *} P<0.001 . \\
& { }^{* * * *} P<0.0001
\end{aligned}
$$


Table 7

Multiple regression analysis table (Statistical Analysis System: PROC GLM Error type III) between school-age children's head circumference-for-age Z-score (Z-HC) (dependent variable) and most relevant parameters (independent variables) ${ }^{\mathrm{a}}$

\begin{tabular}{|c|c|c|c|c|c|c|}
\hline Parameter & Estimate & $\begin{array}{l}T \text { for } \mathrm{HO}: \\
\text { parameter }=0\end{array}$ & $\operatorname{Pr}>[T]$ & $\begin{array}{l}\text { Standard error } \\
\text { of estimate }\end{array}$ & Partial $r^{2}$ & $\begin{array}{l}\% \text { of the explained } \\
\text { variance }\end{array}$ \\
\hline Intercept & -12.58293588 & 3.33 & 0.0017 & 3.78328904 & & \\
\hline Age & -0.02773961 & 0.19 & 0.8514 & 0.14731657 & - & - \\
\hline Sex & & & & & - & - \\
\hline Males & -0.09790286 & 0.44 & 0.6643 & 0.22417235 & & - \\
\hline Females & 0.00000000 & - & - & - & & - \\
\hline SES & & & & & - & - \\
\hline High & -0.11033484 & 0.54 & 0.5933 & 0.20520157 & & - \\
\hline Low & 0.00000000 & - & - & - & & - \\
\hline UN & & & & & - & - \\
\hline Yes & 0.21685458 & 0.60 & 0.5525 & 0.36245650 & & - \\
\hline No & 0.00000000 & - & - & - & & - \\
\hline Absolute BV & 0.00563919 & 5.04 & 0.0001 & 0.00111827 & 0.568 & 78.1 \\
\hline Z-PHC & 0.28188927 & 2.63 & 0.0116 & 0.10735975 & 0.075 & 10.3 \\
\hline Z-MHC & 0.22542435 & 2.41 & 0.0200 & 0.09364889 & 0.042 & 5.8 \\
\hline BL & 0.08834878 & 2.15 & 0.0364 & 0.04104100 & 0.042 & 5.8 \\
\hline BW & 0.00018131 & 0.80 & 0.4256 & 0.00022562 & - & - \\
\hline
\end{tabular}

${ }^{a}$ Model $r^{2}=0.727$; root MSE, (standard deviation of the dependent variable) $=0.65460692 ;$ model $F$-value $=14.19 ; P<0.0001$. SES, socio-economic stratum; UN, severe undernutrition in the first year of life; BV, brain volume; Z-PHC, paternal head circumference-for-age Z-score; Z-MHC, maternal head circumference-for-age Z-score; BL, birth length; BW, birth weight.

\section{Discussion}

The findings of the present study reveal that independent of age, sex and SES, BV is the most relevant independent variable explaining head size $(78.1 \%$ of the explained variance) entering in the first place in the statistical regression model, followed by paternal and maternal Z-HC and child's $\mathrm{BL}$. The high correlation registered between Z-HC-BV is similar to that reported for infants and children and confirms that $\mathrm{HC}$ is the anthropometric indicator both brain development and nutritional background (Bartholomeusz, Courchesne, \& Karns, 2002; Vernon et al., 2000). At birth, the human brain is at $25 \%$ of its adult volume. It reaches $75 \%$ of its adult volume by the end of the first postnatal year. The remaining $25 \%$ of brain growth is achieved over the next few years of life (Reynolds, Johnston, Dodge, DeKosky, \& Ganguli, 1999). In this context, our results confirm that brain growth is the principal determinant of the growth of the cranial vault, which normally ceases to grow at about 7 years of age; thus, adult head size is a reasonable measure of brain size at the end of brain growth (Reynolds et al., 1999). As a result, in the sample analysed in the present study, the decreased head circumference is proportional to the brain volume. In our study, $\mathrm{HC}$ and $\mathrm{BV}$ registered a positive and significant correlation with parental Z-HC, BW, BL, IQ, SA and AAT and negatively with undernutrition during the first year of life and age.

Paternal and maternal Z-HC entered in second and third place in the statistical regression model, respectively (10.3 and $5.8 \%$ of the explained $\mathrm{HC}$ variance). In twins, their spouses, and their children, parental $\mathrm{HC}$ has been described explaining approximately half the normal variation in head size and, at least in part, presumably genetically determined (Weaver \& Christian, 1980).

Children's BL was the only anthropometric index of prenatal nutrition that entered in the statistical regression model in fourth place explaining 5.8\% of $Z$-HC variance. The highest correlation for BL was found with undernutrition in the first year of life and this could be and indicator of the impact of a more deprived nutritional background on HC. In consequence, the magnitude of the decrease of $\mathrm{HC}$ is a reliable indicator of the severity of nutritional deprivation (Winick \& Rosso, 1969a,b). HC has been recognised as the most sensitive anthropometric index of prolonged undernutrition during infancy, associated with intellectual impairment especially verbal IQ, such as in our study (Ivanovic et al., 2000d; Leiva et al., 2001; Stoch et al., 1982). Undernutrition was significantly more prevalent in children with a low HC $(<-2$ S.D.) who presented the lowest verbal IQ, BV and APD values and this latter finding is especially outstanding since APD involves language and visualisation areas (Stoch et al., 1982; Willerman et al., 1991); this could explain that in children with low $\mathrm{HC}(<-2$ S.D.), verbal skills are more deteriorated than non-verbal skills (Ivanovic et al., 2000d; Stoch et al., 1982). In children with HC >2 S.D., verbal IQ was higher than nonverbal IQ and in groups with a "normal $\mathrm{HC}$ " (mean \pm 2 S.D.) similar values were found between total, verbal and non-verbal IQ although IQ was significantly higher in 0-2 S.D. group. Findings from several studies emphasise that among preschoolers $\mathrm{HC}$ might reflect better than body $H$ the impact of nutritional deficiencies at an early age; this measurement is useful in the identification of the period during which malnutrition occurred (Johnston \& Lampl, 1984; Malina et al., 1975). Currently, undernutrition 
constitutes the most important nutritional problem in developing countries where, at an early age, it affects the growth and development of children and may alter brain development and intelligence; poverty and deprivation exacerbate these negative effects, especially when mothers have poor schooling and low intellectual levels (Brown \& Pollitt, 1996; Ivanovic et al., 2000d, 2002; Leiva et al., 2001; Pollitt, 2002). In the high SES, the prevalence of undernutrition is very low and it does not occur generally during the first year of life (Ivanovic, Olivares, \& Ivanovic, 1991). When mothers of the high SES work and their children are cared for by domestic personnel, malnutrition may result from lack of proper nutrition, but despite of this, the effects of undernutrition are ameliorated by the better socio-economic conditions and stimulation. Even more, if mothers have anorexia nervosa their children can suffer from undernutrition, they are more likely to be born prematurely with lower birth weight and length and with serious difficulties in maintaining breastfeeding (Waugh \& Bulik, 1999). Furthermore, mothers from the high SES with low IQ have infants with a lowered HC, BV, IQ, SA and AAT, similarly to low SES infants from mothers with low IQ (Ivanovic et al., 2002). Malnutrition has been associated with retarded BW, BL, HC, BV, APD, IQ, SA, AAT and altered functional development that persist into adult life (Brown \& Pollitt, 1996; FAO, 1996; Fattal-Valevski et al., 1999; Grantham-McGregor \& Fernald, 1997; Ivanovic, 1996; Ivanovic et al., 2000d, 2002; Leiva et al., 2001; Stoch et al., 1982; UNICEF, 2003; Winick \& Rosso, 1969a,b). It is important to underline that these interrelationships do not have direct cause-effect relationships since complex interactions are established between them (Brown \& Pollitt, 1996); SES is co-determinant of nutritional status, HC, brain development, IQ, SA and AAT.

The results of this study demonstrate that children with a low $\mathrm{HC}$ had a decreased BV, APD, BW, BL, BMI, \% AC/A, $\%$ AMA $/ A$, IQ, SA and AAT and parental HC, and higher incidence of undernutrition in the first year of life, compared with their peers with higher Z-HC values, even when considering that these children were significantly younger than the former. Our findings reveal that $\mathrm{HC}$ is positively and significantly correlated with indicators of prenatal nutrition like BW and $\mathrm{BL}$ and children with a low $\mathrm{HC}$ also had a more negative postnatal nutritional environment, a more deteriorated current nutritional status, lower IQ and learning problems (Larroque, Bertrais, Czernichow, \& Leger, 2001; Lundgren, Cnattingius, Jonsson, \& Tuvemo, 2001; Markestad et al., 1997; Matte et al., 2001; Nelson, Goldenberg, Hoffman, \& Cliver, 1997; Sorensen et al., 1999).

The impact of genetic factors should be taken into consideration since parental $\mathrm{HC}$ contributed to explain the child's $\mathrm{HC}$ variance and these factors also affect $\mathrm{HC}, \mathrm{BV}$ and IQ. It is possible that other environmental and genetic factors, which were not evaluated, could affect BW, BL, HC, BV, IQ, SA and AAT. It has been shown that genetic factors affect the growth of children with very low BW, HC, BV and IQ and, as we stated previously, it has been estimated that additive genetic effects probably explain half of the phenotypic variance for HC and IQ (Bouchard, 1998; Casto et al., 1995; McGue \& Bouchard, 1998; Strauss \& Dietz, 1998; Weaver \& Christian, 1980). The intrauterine environment could play a substantial role in the early stages of physical development in children in relation to $W, H$ and $\mathrm{HC}$, but further analyses are needed to clarify how this environment affects child growth and for how long (Livshits, Peter, Vainder, \& Hauspie, 2000).

Several authors have shown a positive and significant correlation among HC, BV and IQ and it seems likely that in the general population the true correlation between HC-IQ and between BV-IQ would be no less than 0.40 and equally strong in males and in females, which is in agreement with our results (Botting et al., 1998; Dolk, 1991; Gignac, Vernon, \& Wickett, 2002; Ivanovic et al., 2000a,b,d; Nelson \& Deutschberger, 1970; Ounsted et al., 1988; Reiss et al., 1996; Rushton, 2000; Strauss \& Dietz, 1998; Vernon et al., 2000; Wickett, Vernon, \& Lee, 1994; Willerman et al., 1991). In this manner, most studies confirm that a lowered $\mathrm{HC}$ or BV was associated with low IQ, SA and AAT (Bouchard, 1998; Desch et al., 1990; Gignac et al., 2002; Ivanovic et al., 2000a,b,d, 2002; Reynolds et al., 1999; Rushton, 2000; Vernon et al., 2000; Weinberg, Dietz, Penick, \& McAlister, 1974); however, other authors did not find significant differences between the mean IQs of the study subjects (HC $<-2$ S.D.) and normal controls, although mean academic achievement scores were significantly lower in the former (Przytycki \& Burgin, 1992; Sells, 1977). Other investigators found that non-organic failure to thrive in infancy is followed by persistent stunting and wasting and a reduced $\mathrm{HC}$ but it is not associated with cognitive or educational disadvantages at school age (Drewett, Corbett, \& Wright, 1999).

In the present study, despite the fact that very few cases were found in the extreme categories for Z-HC, the distribution of the sample in the different $Z$-HC categories is similar to that found in the 1986-1987 survey carried out in a representative sample of 4509 school-age children from elementary and high schools, in Chile's Metropolitan Region (Ivanovic et al., 1995). This may indicate that independently of sample size, the distribution of children according to $\mathrm{Z}$-HC categories in the Chilean school-age population is similar. Even more, 100.0 and $60.0 \%$ of school-age children with $Z$-HC values $<-2$ S.D. (microcephaly) and between -2 and $<0$ S.D., respectively, had low IQ; the opposite was observed for categories 0-2 S.D. and >2 S.D. (macrocephaly) in which 66.7 and $100 \%$, respectively, exhibited high IQ (Fig. 1). Therefore, we emphasise that a "normal" $\mathrm{HC}$ (mean \pm 2 S.D.) is more related to statistical normality, although this may not be so for psychological or educational achievements. In fact, $\mathrm{HC}$ values below the mean are associated with an increased incidence of lower IQ; this means that small differences in $\mathrm{HC}$ could be of considerable importance in the interrelationship between HC and IQ (Ivanovic et al., 2000b). The findings of this study should be considered as statistical associations and do not 
represent a cause-and-effect relationship. This is a matter in which further research should be carried out. In the present study, as already stated, very few cases in the extreme categories of Z-HC were found, but despite of this, results are significant and eloquent and are in agreement with our previous findings in larger samples (Ivanovic et al., 1995). The results of the present study demonstrate that $\mathrm{HC}$ and $\mathrm{BV}$ values are related more to differences in IQ and not to SES conditions.

"Primary" microcephaly means an abnormal $\mathrm{HC}$ at birth and "secondary" microcephaly a normal HC at birth, with microcephaly acquired later due to deceleration of brain growth reflecting infections, trauma, intoxications, metabolic diseases, the Rett syndrome, or central nervous system degenerative diseases (Opiz \& Holt, 1990). On the other side, primary megalencephaly at birth had been described as a risk factor for low levels of intelligence but not for visual and auditive impairments (Petersson, Pedersen, Schalling, \& Lavebratt, 1999). Based on the results of this study and on our previous findings we contend that, at school age, children with $\mathrm{HC}$ values $<-2$ and $>2$ S.D. had low and high IQ, respectively. In this sample of children, mothers reported that their children had never been diagnosed as being microcephalic or macrocephalic and for this reason the etiologies remain unknown.

Some authors have pointed out that larger brains have more neurons and therefore, a greater number of synaptic connections, which may mean a higher IQ (Pakkenberg \& Gundersen, 1997). It has been suggested that individual differences in myelination, which affects neural transmission rates, may be the basis for the HC-BV-IQ correlation although there is a low correlation between neural speed and mental speed, suggesting that other mechanisms must be involved (Miller, 1994; Tan, 1996; Vargas et al., 2000; Wickett \& Vernon, 1994). Delayed myelination and abnormalities in neuron migration have been described as the most predominant disorders in children with associated neurologic findings, whereas focal white matter lesions were more common in children without neurologic symptoms; these alterations were significantly more common in children with a small HC (Kjos, Umansky, \& Barkovich, 1990).

This multifactorial study provides substantial evidence at 18 years of age for associations between head size and measures of brain size, nutritional status, IQ, learning and parental HC. These findings confirm the hypothesis that: (1) independently of age, sex and SES, brain parameters, parental $\mathrm{HC}$ and prenatal nutritional indicators are the most important independent variables that determine children's $\mathrm{HC}$ and (2) microcephalic children (Z-HC $<-2$ S.D.) present multiple disorders not only related to $\mathrm{BV}$ but also to IQ, SA and nutritional background, variables that are significantly interrelated. These results may be useful for the understanding of human behaviour related to disorders of intellectual and learning achievements when children present with decreased $\mathrm{HC}$ resulting from a lower brain size and a deprived nutritional background, especially prenatally.

\section{Acknowledgements}

The authors are very gratefully to the Ministry of Education of Chile for all the facilities given to carry out this research; to Dr. Oscar Brunser MD, for helpful comments and suggestions. Supported in part by Grant 1961032 from the National Fund for Scientific and Technologic Development (FONDECYT), Grant 024/1997 from the University of Chile, Postgradest Department and Grant SOC 01/13-2 from the Research Department (DI), University of Chile.

\section{References}

Alvarez, M. L., Muzzo, S., \& Ivanovic, D. (1985). Escala para medición del nivel socioeconómico en el área de la salud. Revista Médica de Chile, 113, 243-249.

Anderson, B. (1999). Brain size, head size, and intelligence quotient in monozygotic twins. Neurology, 53, 239.

Baker, L. A., Treloar, S. A., Reynolds, C. A., Heath, A. C., \& Martin, N. G. (1996). Genetics of educational attainment in Australian twins: Sex differences and secular changes. Behavior Genetics, 26, 89-102.

Bartholomeusz, H. H., Courchesne, E., \& Karns, C. M. (2002). Relationship between head circumference and brain volume in healthy normal toddlers, children, and adults. Neuropediatrics, 33, 239-241.

Botting, N., Powls, A., Cooke, R. W., \& Marlow, N. (1998). Cognitive and educational outcome of very low-birth weight children in early adolescence. Developmental Medicine and Child Neurology, 40, 652660 .

Bouchard Jr., T. J. (1998). Genetic and environmental influences on adult intelligence and special mental abilities. Human Biology, 70, 257-279.

Brown, L., \& Pollitt, E. (1996). Malnutrition, poverty and intellectual development. Scientific American, 274, 38-43.

Casto, S. D., DeFries, J. C., \& Fulker, D. W. (1995). Multivariate genetic analysis of Wechsler Intelligence Scale for Children-Revised (WISC-R) factors. Behavior Genetics, 25, 25-32.

Chile Ministerio de Educación Pública (1996). Planes y Programas de Estudio para la Educación Media. Revista de Educación, 225. Santiago: MINEDUC.

Desch, L. W., Anderson, S. K., \& Snow, J. H. (1990). Relationship of head circumference to measures of school performance. Clinical Pediatrics, 29, 389-392.

Dolk, H. (1991). The predictive value of microcephaly during the first year of life for mental retardation at seven years. Developmental Medicine and Child Neurology, 33, 974-983.

Drewett, R. F., Corbett, S. S., \& Wright, C. M. (1999). Cognitive and educational attainments at school age of children who failed to thrive in infancy: A population-based study. Journal of Child Psychology and Psychiatry and Allied Disciplines, 40, 551-561.

FAO. (1996). Sexta Encuesta Alimentaria Mundial. Roma: FAO.

Fattal-Valevski, A., Leitner, Y., Kutai, M., Tal-Posener, E., Tomer, A., \& Lieberman, D. et al., (1999). Neurodevelopmental outcome in children with intrauterine growth retardation: A 3-year follow-up. Journal of Child Neurology, 14, 724-727.

Frisancho, A. R. (1981). New norms of upper limb fat and muscle areas for assessment of nutritional status. American Journal of Clinical Nutrition, 34, 2540-2545.

Frodl, T., Meisenzahl, E. M., Muller, D., Greiner, J., Juckel, G., \& Leinsinger, G. (2001). Corpus callosum and P300 in schizophrenia. Schizophrenia Research, 49, 107-119.

Garrow, J.S. (1981). Treat obesity seriously: A clinical manual. London: Churchill Livingstone.

Gibson, R. (1990). Principles of nutritional assessment. Oxford: Oxford University Press. 
Gignac, G., Vernon, P. A., Wickett, J. C. (2002). Factors influencing the relationship between brain size and intelligence. In H. Nyborg (Ed.), The scientific study of general intelligence: Tribute to Arthur R. Jensen (pp. 93-106). Oxford, UK: Elsevier.

Grantham-McGregor, S. M., \& Fernald, L. C. (1997). Nutritional deficiencies and subsequent effects on mental and behavioral development in children. Southeast Asian Journal of Tropical Medicine and Public Health, 28, 50-68.

Guilford, J. P., Fruchter, B. (1984). Estadística Aplicada a la Psicología y a la Educación. México: McGraw Hill.

Hermosilla, M. (1986). La escala de inteligencia de Wechsler para adultos (WAIS). Santiago: Pontificia Universidad Católica de Chile, Escuela de Psicología.

Ivanovic, D. (1996). Does undernutrition during infancy inhibit brain growth and subsequent intellectual development? Prospective overview. Nutrition, 12, 568-571.

Ivanovic, D., Almagià, A., Toro, T., Castro, C., Pérez, H., \& Urrutia, M. S. et al., (2000a). Impacto del estado nutricional en el desarrollo cerebral, inteligencia y rendimiento escolar, en el marco de un enfoque multifactorial. La Educación (Organización de los Estados Americanos, OEA), 44, 3-35.

Ivanovic, R., Forno, H., Castro, C. G., \& Ivanovic, D. (2000b). Intellectual ability and nutritional status assessed through anthropometric measurements of Chilean school-age children from different socioeconomic status. Ecology of Food and Nutrition, 39, 35-59.

Ivanovic, R., Forno, H., Durán, M. C., Hazbún, J., Castro, C., \& Ivanovic, D. (2000c). Estudio de la capacidad intelectual (Test de Matrices Progresivas de Raven) en escolares de 5 a 18 años. I. Antecedentes generales, normas y recomendaciones. Región Metropolitana, Chile, 1986-1987. Revista de Psicología General y Aplicada, 53, 5-30.

Ivanovic, D., Forno, H., \& Ivanovic, R. (2001). Estudio de la capacidad intelectual (Test de Matrices Progresivas de Raven) en escolares de 5 a 18 años. II. Interrelaciones con factores socioeconómicos, socioculturales, familiares, de exposición a medios de comunicación de masas, demográficos y educacionales. Revista de Psicología General y Aplicada, 54, 443-466.

Ivanovic, D., Ivanovic, R., Truffello, I., \& Buitrón, C. (1989). Nutritional status and educational achievement of elementary first grade Chilean students. Nutrition Reports International, 39, 163-175.

Ivanovic, D., Leiva, B., Pérez, H., Almagià, A., Toro, T., \& Urrutia, M. S. et al., (2002). Nutritional status, brain development and scholastic achievement of Chilean high school graduates from high and low intellectual quotient and socio-economic status. British Journal of Nutrition, 87, 81-92.

Ivanovic, D., Leiva, B., Pérez, H., Inzunza, N., Almagià, A., \& Toro, T. et al., (2000d). Long-term effects of severe undernutrition during the first year of life on brain development and learning in Chilean high school graduates. Nutrition, 16, 1056-1063.

Ivanovic, D., Olivares, M., Castro, C., \& Ivanovic, R. (1995). Circunferencia craneana de escolares chilenos de 5 a 18 años. Región Metropolitana de Chile, 1986-1987, 1992. Revista Médica de Chile, $123,587-599$.

Ivanovic, D., Olivares, M., Castro, C., \& \& Ivanovic, R. (1996). Nutrition and learning in Chilean school-age children. Chile's Metropolitan area. Survey 1986-1987. Nutrition, 12, 321-328.

Ivanovic, D., Olivares, M., \& Ivanovic, R. (1991). Nutritional status of Chilean school children from different socioeconomic status and sex. Chile's Metropolitan Region. Survey 1986-1987. Ecology of Food and Nutrition, 26, 1-16.

Johnston, F., Lampl, M. (1984). Anthropometry in studies of malnutrition and behavior. In J. Brozek, B. Schurch (Eds.), Malnutrition and behavior: Critical assessment of key issues (pp. 51-70). Lausanne, Switzerland: Nestlé Foundation.

Kjos, B. O., Umansky, R., \& Barkovich, A. J. (1990). Brain MR imaging in children with developmental retardation of unknown cause: Results in 76 cases. American Journal of Neuroradiology, 11, 1035-1040.
Larroque, B., Bertrais, S., Czernichow, P., \& Leger, J. (2001). School difficulties in 20-year-olds who were born small for gestational age at term in a regional cohort study. Pediatrics, 108, 111-115.

Leiva, B., Inzunza, N., Pérez, H., Castro, V., Jansana, J. M., \& Toro, T. et al., (2001). Algunas consideraciones sobre el impacto de la desnutrición en el desarrollo cerebral, inteligencia y rendimiento escolar. Archivos Latinoamericanos de Nutrición, 51, 64-71.

Livshits, G., Peter, I., Vainder, M., \& Hauspie, R. (2000). Genetic analysis of growth curve parameters of body weight, height and head circumference. Annals of Human Biology, 27, 299-312.

Luke, B., Keith, L., \& Keith, D. (1997). Maternal nutrition in twin gestations: Weight gain, cravings and aversions, and sources of nutrition advice. Acta Geneticae Medicae et Gemellologiae (Roma), 46, 157166.

Lundgren, E. M., Cnattingius, S., Jonsson, B., \& Tuvemo, T. (2001). Intellectual and psychological performance in males born small for gestational age with and without catch-up growth. Pediatric Research, 50, 91-96.

Malina, R. M., Habicht, J. P., Martorell, R., Lechtig, A., Yarbrough, C., \& Klein, R. E. (1975). Head and chest circumferences in rural Guatemalan Ladino children, birth to seven years of age. American Journal of Clinical Nutrition, 28, 1061-1070.

Markestad, T., Vik, T., Ahlsten, G., Gebre-Medhin, M., Skjaerven, R., \& Jacobsen, G. et al., (1997). Small-for-gestational-age (SGA) infants born at term: Growth and development during the first year of life. Acta Obstetricia et Gynecologica Scandinavica Supplement, 165, 93-101.

Martyn, C. N., Gale, C. R., Sayer, A. A., \& Fall, C. (1996). Growth in utero and cognitive function in adult life: Follow up study of people born between 1920 and 1943. British Medical Journal, 312, 13931396.

Matano, S., \& Nakano, Y. (1998). Size comparison of the male and female human corpus callosum from autopsy samples. Zeitschrift fur Morphologie und Anthropologie, 82, 67-73.

Matte, T. D., Bresnahan, M., Begg, M. D., \& Susser, E. (2001). Influence of variation in birth weight within normal range and within sibships on IQ at age 7 years: Cohort study. British Medical Journal, 323, 310-314.

McGue, M., \& Bouchard Jr., T. J. (1998). Genetic and environmental influences on human behavioral differences. Annual Review of Neuroscience, 21, 1-24.

Menkes, J. H. (1995). Textbook of child neurology. Baltimore: Williams and Wilkins.

Miller, E. M. (1994). Intelligence and brain myelination: A hypothesis. Personality and Individual Differences, 17, 803-832.

Nelson, K. B., \& Deutschberger, J. (1970). Head size at 1 year as a predictor of 4-year IQ. Developmental Medicine and Child Neurology, 12, 487-495.

Nelson, K. G., Goldenberg, R. L., Hoffman, H. J., \& Cliver, S. P. (1997). Growth and development during the first year in a cohort of low income term-born American children. Acta Obstetricia et Gynecologica Scandinavica Supplement, 165, 87-92.

Nellhaus, G. (1968). Head circumference from birth to eighteen years. Pediatrics, 41, 106-114.

Opiz, J. M., \& Holt, M. C. (1990). Microcephaly: General considerations and aids to nosology. Journal of Craniofacial Genetics and Developmental Biology, 10, 175-204.

Ounsted, M., Moar, V. A., \& Scott, A. (1988). Head circumference and developmental ability at the age of 7 years. Acta Paediatrica Scanddinavica, 77, 374-379.

Pakkenberg, B., \& Gundersen, H. J. G. (1997). Neocortical neuron number in humans: Effect of sex and age. Journal of Comparative Neurology, 384, 312-320.

Pennington, B. F., Filipek, P. A., Lefly, D., Chhabildas, N., Kennedy, D. N., \& Simon, J. H. et al., (2000). A twin MRI study of size variations in human brain. Journal of Cognitive Neuroscience, 12, 223-232.

Peters, M., Jancke, L., Staiger, J. F., Schlaug, G., Huang, Y., \& Stenmetz, H. (1998). Unsolved problems in comparing brain sizes in homo sapiens. Brain and Cognition, 37, 254-285. 
Petersson, S., Pedersen, N. L., Schalling, M., \& Lavebratt, C. (1999). Primary megalencephaly at birth and low intelligence level. Neurology, 53, 1254-1259.

Pollitt, E. (2002). Consecuencias de la desnutrición en el escolar peruano. Lima: Fondo Editorial de la Pontificia Universidad Católica.

Przytycki, A., \& Burgin, R. (1992). Microcephalic children without mental retardation. Harefuah, 122, 566-568.

Reiss, A. L., Abrams, M. T., Singer, H. S., Ross, J. L., \& Denckla, M. B. (1996). Brain development, gender and IQ in children. A volumetric imaging study. Brain, 119, 1763-1774.

Reynolds, M. D., Johnston, J. M., Dodge, H. H., DeKosky, S. T., \& Ganguli, M. (1999). Small head size is related to low Mini-Mental State Examination scores in a community sample of nondemented older adults. Neurology, 53, 228-229.

Roche, A. F., Mukherjee, D., Guo, S., \& Moore, W. (1987). Head circumference reference data: Birth to 18 years. Pediatrics, 79, 706712.

Rushton, J. P. (2000). Race, evolution, and behavior: A life-history perspective (2nd special abridged edition). Port Huron, MI: Charles Darwin Research Institute.

SAS. (1983). SAS Introductory Guide. Statistics. North Caroline: SAS Institute Inc.

Schoenemann, P. T., Budinger, T., Sarich, V., \& Wang, W. (2000) Brain size does not predict general cognitive ability within families. Proceedings of the National Academy of Sciences of USA, 97, 49324937.

Schofield, P. W., Logroscino, G., Andrews, H. F., Albert, S., \& Stern, Y. (1997). An association between head circumference and Alzheimer's disease in a population-based study of aging and dementia. Neurology, 49, 30-37.

Sells, C. J. (1977). Microcephaly in a normal school population. Pediatrics, 59, 262-265

Sorensen, H. T., Sabroe, S., Olsen, J., Rothman, K. J., Gillman, M. W., \& Fisher, P. (1999). Birth weight as a predictor of young men's intelligence. A historical cohort study. Ugeskrift for Laeger, 161, 791793.

Stathis, S. L., O’Callaghan, M., Harvey, J., \& Rogers, Y. (1999). Head circumference in ELBW babies is associated with learning difficulties and cognition but not ADHD in the school-aged child. Developmental Medicine and Child Neurology, 41, 375-380.

Stoch, M. B., Smythe, P. M., Moodie, A. D., \& Bradshaw, D. (1982). Psychosocial outcome and CT findings after gross undernourishment during infancy: A 20-year developmental study. Developmental Medicine and Child Neurology, 24, 419-436.

Strauss, R. S., \& Dietz, W. H. (1998). Growth and development of term children born with low birth weight: Effects of genetic and environmental factors. Journal of Pediatrics, 133, 67-72.

Tan, Ü. (1996). Correlations between nonverbal intelligence and peripheral nerve conduction velocity in right-handed subjects: Sex-related differences. International Journal of Psychophysiology, 22, 123-128.

Tanner, J. M. (1984). Physical growth and development. In J. O. Forfar, G. C. Arneil (Eds.), Textbook of pediatrics (pp. 278-330). Edinburgh: Churchill Livingstone.
Teasdale, T. W., \& Pakkenberg, B. (1988). The association between intelligence level and brain volume measures: A negative finding. Scandinavian Journal of Psychology, 29, 123-125.

The World Medical Association. (1964). Human experimentation. Code of Ethics of the World Medical Association (Declaration of Helsinki). British Medical Journal, 2, 177.

Tisserand, D. J., Bosma, H., Van Boxtel, M. P., \& Jolles, J. (2001). Head size and cognitive ability in nondemented older adults are related. Neurology, 56, 969-971.

Toro, T., Almagià, A., \& Ivanovic, D. (1998). Evaluación antropométrica y rendimiento escolar en estudiantes de educación media de Valparaíso, Chile. Archivos Latinoamericanos de Nutrición, 48, 201-209.

UNICEF. (1994). Una propuesta de clasificación de las comunas del país según la situación de la infancia. Santiago: UNICEF.

UNICEF. (2003). Estado mundial de la infancia. Nueva York: UNICEF.

Vargas, V., Vargas, R., Marquez, G., Vonasek, E., Mateu, L., \& Luzzati, V. et al., (2000). Malnutrition and myelin structure: An X-ray scattering study of rat sciatic and optic nerves. European Biophysics Journal, 29, $481-486$.

Vernon, P. A., Wickett, J. C., Bazana, P. G., Stelmack, R. M. (2000). The neuropsychology and psychophysiology of human intelligence. In R. J. Sternberg (Ed.), Handbook of intelligence (pp. 245-264). Cambridge: Cambridge University Press.

Waugh, E., \& Bulik, C. M. (1999). Offspring of women with eating disorders. International Journal of Eating Disorders, 25, 123133.

Weaver, D. D., \& Christian, J. C. (1980). Familial variation of head size and adjustment for parental head circumference. Journal of Pediatrics, 96, 990-994.

Wechsler, D. (1981). Manual for the Wechsler Adult Intelligence Scale-Revised. New York, NY: Psychological Corporation.

Weinberg, W. A., Dietz, S. G., Penick, E. C., \& McAlister, W. H. (1974). Intelligence, reading achievement, physical size and social class. A study of St. Louis Caucasian boys aged 8-0 to 9-6 years, attending regular schools. Journal of Pediatrics, 85, 482-489.

WHO. (1980). Measurement of the nutritional impact of supplementation food programs to vulnerable groups. FAP/79.1. Ginebra: WHO.

Wickett, J. C., \& Vernon, P. A. (1994). Peripheral nerve conduction velocity, reaction time, and intelligence: An attempt to replicate Vernon and Mori (1992). Intelligence, 18, 27-131.

Wickett, J. C., Vernon, P. A., \& Lee, D. H. (1994). In vivo brain size, head perimeter, and intelligence in a sample of healthy adult females. Personality and Individual Differences, 16, 831-838.

Willerman, L., Schultz, R., Rutledge, J. N., \& Bigler, D. E. (1991). In vivo brain size and intelligence. Intelligence, 15, 223-228.

Winick, M., \& Rosso, P. (1969a). Head circumference and cellular growth of the brain in normal and marasmic children. Journal of Pediatrics, 74, 774-778.

Winick, M., \& Rosso, P. (1969b). The effect of severe early malnutrition on cellular growth of human brain. Pediatric Research, 3, 181-184.

Yeo, R. A., Turkheimer, E., Raz, N., \& Bigler, E. D. (1987). Volumetric asymmetries of the human brain: Intellectual correlates. Brain and Cognition, 6, 15-23. 